\title{
A gestão da experiência do cliente no varejo
}

\author{
The management of retail customer experience
}

Ana Rita Catelan Callegare ${ }^{[a]}$, Vinícius Sittoni Brasil ${ }^{[b]}$

[a] Doutoranda em Administração pela Pontifícia Universidade Católica do Rio Grande do Sul (PUCRS), Porto Alegre, RS - Brasil; e-mail: anarita_cc@yahoo.com.br

[b] Doutor em Marketing pela Universidade Federal do Rio Grande do Sul (UFRGS), professor titular do Programa de Pós-graduação em Administração da Pontifícia Universidade Católica do Paraná (PUCRS), Porto Alegre, RS - Brasil, e-mail: vinicius@pucrs.br

\section{Resumo}

Diversos autores destacam o papel central dos componentes experienciais no consumo, e significativos esforços de pesquisa em marketing são direcionados ao entendimento das experiências de consumo sob a ótica do consumidor. Porém a implantação da Gestão da Experiência do Cliente (GEC), pelas empresas, tem recebido menor atenção. Schmitt, Prahalad e Ramaswamy destacam a necessidade de as empresas planejarem adequadamente a proposta experiencial, estruturando mecanismos capazes de proporcionar ao consumidor a oportunidade de cocriar valor, a partir de suas interações com empresa, marca ou produto. Este artigo se propõe a discutir um caso de implantação da GEC no contexto varejista. A partir de entrevistas com gestores, observação em lojas e análise de dados secundários, buscou-se contrapor a proposta da empresa com os modelos teóricos, em particular do Modelo DART. Os resultados apontam para a boa convergência entre teoria e prática, demonstrando as características individuais da experiência, bem como sustenta a GEC como uma opção ao posicionamento estratégico no varejo. Igualmente, identificam-se elementos alinhados com o Modelo DART.

Palavras-chave: Gestão das experiências do consumidor. Modelo DART. Varejo.

\section{Abstract}

Several authors emphasize the central role of the components of experiential consumption and significant Marketing research efforts are directed to understand the consume experiences in the consumer point of view. However, the implementation of Customer Experience Management (CEM) by the companies has received less attention. Schmitt, Prahalad and Ramaswamy highlight the need to properly plan the experiential proposal to provide consumers the opportunity to co-create value from their interactions with companies, brands or products. This article aims to discuss a case of implantation of the CEM in the retailer context. Based on interviews with managers, stores observation and secondary data analysis, we sought to counter the company's proposal with the theoretical models, particularly the DART Model. The result indicate a good convergence between theory and 
practice, demonstrating the characteristics of individual experience as well as supports the CEM as an alternative to strategic positioning in retail. Also, it identifies elements aligned with the DART Model.

Keywords: Costumer experience management. DART model. Retailing.

\section{Introdução}

O setor de Varejo representa um dos contextos mais plurais para a investigação de marketing, tendo em vista suas características específicas, mesclando atividades típicas de serviços (por exemplo, atendimento e design do ambiente de loja) com desafios presentes no meio industrial (gestão de estoques e eficiência logística). Do ponto de vista estratégico, a definição das bases para o correto posicionamento de uma empresa de Varejo constitui elemento-chave para a sua performance. Empresas de diferentes categorias exploram posicionamentos distintos, incluindo o foco em preço (como Wal-Mart e Carrefour), variedade de produtos (Lojas Renner e C\&A), serviços (Tok Stok), conveniência (AM-PM) e experiência de consumo (Livraria Cultura Megastore, Colombo Premium e I-Place). Neste trabalho, explora-se especificamente este último enfoque a partir da análise do caso de uma rede lojas de moda jovem, cuja opção estratégica baseia-se em proporcionar uma experiência diferenciada e autêntica a seus clientes.

O estudo de Hirschman e Holbrook (1982) pode ser considerado o precursor da "perspectiva experiencial" do consumo. Esses autores questionam a hegemonia da visão tradicional de marketing a qual poderia negligenciar fenômenos importantes para o entendimento mais profundo do consumo na perspectiva do próprio consumidor. A "visão experiencial" proposta pelos autores caracterizava-se pelo fluxo de fantasias, sentimentos e diversão associadas ao processo de consumo, que, por sua vez, apresentava uma variedade de significados simbólicos, respostas hedônicas e elementos estéticos. Além disto, o marketing tradicional não reflete a complexidade e heterogeneidade do consumidor moderno (ADDIS; HOLBROOK, 2001; GENTILE; SPILLER; NOCI, 2007; YUAN; WU, 2008).

Prahalad e Ramaswamy (2004) destacam o papel central das experiências de consumo na criação de valor compartilhado entre empresas e consumidores e da importância das empresas planejarem suas ações em torno de "ambientes experienciais de cocriação de valor". Esses autores propõem que tais experiências sejam criadas a partir de quatro pilares: diálogo (forma bidirecional de interação e comunicação com o consumidor), acesso (mecanismos que permitam ao consumidor acessar a experiência em diferentes contextos), redução de risco (menor assimetria de informações entre empresa e consumidor) e transparência (maior abertura por parte das empresas e dos consumidores). Essa proposta ficou conhecida como modelo DART. Assim, as organizações devem articular seus esforços de marketing em torno de mecanismos que estimulem a interação e a colaboração com o consumidor, não mais assumindo-o como um agente passivo, mas como um participante ativo da geração de valor a partir de suas próprias experiências com a empresa (LUSCH; VARGO, 2006). A implantação da Gestão da Experiência do Cliente (GEC), nos termos de Schmitt (2004), passa a ser um desafio para as empresas que buscam um posicionamento de mercado baseado na experiência de consumo.

Mas como definir o que é uma experiência? Conforme destacou Brasil (2007), várias lacunas no entendimento sobre a definição e a natureza das experiências de consumo permeiam a literatura de $m a$ rketing. Observa-se que distintos conceitos têm sido empregados acerca do que é uma experiência de consumo e quais são as variáveis que a cercam (GENTILE; SPILER; NOCI, 2007; MEYER; SCHWAGER, 2007; SCHMITT, 2002). As diferentes definições encontradas na literatura destacam desde um caráter relacional, caracterizando a experiência como um conjunto de interações entre a organização/produto e seus consumidores (ADDIS; HOLBROOK, 2001; GENTILE; SPILLER; NOCI, 2007; CARÙ; COVA, 2003; 2007), até um enfoque voltado ao conceito de valor. Nesse caso, as experiências são cocriadas, ou seja, as empresas proporcionam artefatos para os consumidores cocriarem as suas próprias experiências (LASALLE; BRITTON, 2003; LUSCH; VARGO; O'BREIN, 2007; MATHWICK; MALHOTRA; RIGDON, 2001; PRAHALAD; RAMASWAMY, 2003).

Gentile, Spiller e Noci (2007) definem experiência de consumo como algo derivado das diferentes interações do consumidor com a empresa, a marca, os produtos ou outros elementos de contato, resultando 
em eventos estritamente pessoais com diferentes níveis racionais, emocionais, sensoriais, físicos e espitiruais. Verhoef et al. (2009) destacam o caráter holístico de uma experiência, na qual diferentes fatores, tanto controlados pela empresa (por exemplo, produto, ambiente de loja), quanto incontroláveis (caraterísticas do consumidor e fatores situacionais de compra), constituem o contexto no qual a experiência se materializa. Dessa forma, o varejista deve proporcionar de um lado uma proposta experiencial capaz de ser relativamente estável e gerenciada, ao mesmo tempo em que tal proposta permita ao consumidor criar uma experiência individual e autêntica.

Pine II e Gilmore (1998), Dubé, Lê Bel e Sears (2003) e Farias (2010) enfatizam que a experiência deve ser algo memorável e único. Já Schmitt (2002), Prahalad e Ramaswamy (2003) e Pullman e Gross (2003), mesmo identificando a experiência como algo diferenciado, não a colocam necessariamente de forma excepcional e memorável, mas como uma proposta de valor continuamente aprimorada. No contexto varejista, parece razoável assumir a perspectiva experiencial como uma proposta estratégica capaz sustentar uma continuidade no relacionamento com seus clientes, em vez de algo excepcional ou eventual. Conforme destaca Schmitt (2004), a GEC é uma abordagem capaz de proporcionar uma visão total da experiência do cliente em um novo formato de gestão cujo foco não está em aspectos funcionais do produto, mas sim em ações capazes de proporcionar valor durante todo o processo de tomada de decisão de compra.

Nesse sentido, a fim de contribuir para o entendimento da gestão da experiência, o presente artigo propõe-se a analisar o processo de implantação da GEC em uma empresa varejista. São analisadas as ações da empresa em relação aos modelos teóricos presentes na literatura, em particular as propostas de Schmitt (2004) e Prahalad e Ramaswamy (2004). Dessa forma, apresenta-se a seguir o referencial teórico que sustentam o desenvolvimento do estudo de caso. Posteriormente, são detalhados os procedimentos metodológicos utilizados na pesquisa. Por fim, os principais resultados são relatados, subsidiando as conclusões do trabalho.

\section{Referencial teórico}

A base teórica a seguir apresentada divide-se em dois pontos centrais: aspectos conceituais da experiência de consumo e elementos do gerenciamento das experiências do cliente.

\section{Experiências de consumo: definições e abordagens}

Lusch e Vargo (2006) descrevem a nova "lógica dominante" do marketing, denominada Lógica do Serviço-Dominante (LS-D), na qual o papel do consumidor diante do processo de compra/consumo transforma-se de uma postura passiva para uma atitude ativa de coautoria na criação do valor de uso/ consumo. Nesta perspectiva, esses autores destacam que não são os produtos ou ofertas o foco central da ação de marketing, mas sim a experiência de consumo como um todo.

No campo do marketing, nota-se um esforço para chegar a uma definição homogênea do termo "experiência de consumo" que possibilite estabelecer um consenso quanto ao tema. Pine II e Gilmore (1998) apresentaram as experiências de consumo como um avanço às ofertas econômicas - commodities, bens e serviços - caracterizando-as como eventos extraordinários inerentemente pessoais, existindo apenas para os consumidores que, de alguma forma, estivessem engajados em nível emocional, físico, intelectual e espiritual. Contemplando esse ponto de vista, Pullman e Gross (2003) enfatizam que as experiências são inerentemente emocionais e pessoais.

Nos anos seguintes, novas abordagens surgiram, concentrando suas atenções sobre a experiência como forma de criar valor para a empresa e o cliente (LASALLE; BRITTON, 2003; PRAHALAD; RAMASWAMY, 2003; MATHWICK; MALHOTRA; RIGDON, 2001; LUSCH; VARGO; O’BREIN, 2007). 0 ponto em comum dessas abordagens está em analisar a experiência como forma de envolver o indivíduo como um todo, em diferentes níveis, a cada interação com a empresa. Contrapondo-se à visão de Pine II e Gilmore (1998), LaSalle e Britton (2003) afirmam que a criação de valor não está especificamente em vender experiências memoráveis, mas permitir ao consumidor vivenciar todos os momentos da relação com a empresa, de forma que esta passe a ser identificada com as expectativas, os valores e o estilo de vida do consumidor. Além disso, nesta perspectiva, as empresas não "vendem" experiências, mas fornecem artefatos e contextos favoráveis para cocriarem as suas próprias e únicas experiências (CARÙ; COVA, 2003; 2007). 
Aproximando as experiências de consumo do conceito de valor, Prahalad e Ramaswamy (2003) apontam que a criação de valor é definida pela experiência individual de um consumidor, em determinado contexto. Assim, são os indivíduos e suas interações que definem a experiência e o valor oriundos dela. Sob a ótica de Mathwick, Malhotra e Rigdon (2001), o valor percebido através de uma experiência baseia-se nas interações presentes tanto no uso direto, quanto na apreciação à distância de bens e serviços, podendo gerar benefícios tanto extrínsicos (considerados utilitários e funcionais), quanto intrínsicos (de caráter individual e emocional). Além disso, as experiências se tornam uma condição necessária para a determinação de valor, pois não existe valor em produtos/serviços até que eles sejam utilizados (LUSCH; VARGO; O'BREIN, 2007).

Brasil (2007) destaca que podem ser consideradas duas bases fundamentais para o entendimento das experiências de consumo: primeiro, seu caráter vivencial e, por conseguinte, o seu caráter individual. Estas premissas encontram respaldo nas ideias propostas por Pullman e Gross (2003), ao afirmarem que todas as definições possuem em comum a interação do consumidor com diferentes elementos da empresa. Schmitt (2002) reitera as bases fundamentais associadas às experiências de consumo, afirmando que elas são resultado do encontro e da vivência de situações as quais dão respaldo ao seu caráter prático e funcional, ao mesmo tempo em que são acontecimentos que ocorrem em nível individual e geram respostas a um estímulo. Gentile, Spiller e Noci (2007), alinhados às ideias propostas por Schmitt (2002), reiteram que as experiências podem ser denominadas como um conjunto de interações entre uma organização e/ou clientes que de alguma forma provoque uma reação.

\section{Gestão da experiência}

Schmitt (2002) afirma que os profissionais de $m a$ rketing precisam identificar os cenários e ambientes adequados para que as experiências que os consumidores desejam viver possam, efetivamente, acontecer. Além disso, são os gestores de marketing que fornecem os estímulos capazes de produzir experiências aos consumidores; neste caso, são eles que escolhem os meios "provedores de experiência". Isso não significa dizer que o cliente se mantenha passivo nesse processo, mas é de responsabilidade da empresa tomar a iniciativa. Os "provedores de experiência" identificados na literatura dependem do meio pelo qual um consumidor irá obter essa experiência. A experiência pode ocorrer quando os consumidores estão em busca de um produto, quando compram o produto ou serviço, ou no momento do consumo em si (BRAKUS; SCHMITT; ZARANTONELLO, 2009).

Uma das importantes decisões a serem tomadas pelos profissionais de marketing, ao invés de se preocuparem apenas com uma experiência isolada, é o de identificar quais são os tipos de experiências que querem provocar nos seus consumidores e como fornecê-las de modo adequado (SCHMITT, 2002). Brakus, Schmitt e Zarantonello (2009) sintetizam a ideia de que, acima de tudo, considerando-se os meios provedores de experiência, quando os consumidores pesquisam, compram e consomem, eles estão tendo uma experiência com a marca.

Estudos recentes procuram desenvolver estruturas teóricas capazes de orientar a implantação e a investigação acerca das experiências de consumo. Grewal, Levy e Kumar (2009) organizam um modelo estrutural relacionado a macrofatores que influenciam a experiência do consumidor e que estão sob o controle do varejista (promoção, preço, produto, cadeia de suprimento e localização). Verhoef et al. (2009) analisam que, além dos fatores sob controle dos varejistas, outros podem impactar a experiência do consumidor - por exemplo, os processos de decisão de compra e suas influências - e as interações sociais com outros consumidores. Schmitt (2004) traça cinco etapas para o gerenciamento da experiência do consumidor: a) análise do mundo experiencial do cliente (analisar o contexto sociocultural em que esses clientes estão inseridos, suas necessidades, preferências e estilos de vida); b) construção da plataforma experiencial (ponto de ligação entre a estratégia e a implantação, ou seja, uma representação multissensorial e multidimensional da experiência pretendida); c) projeto da experiência da marca (consiste na implantação da experiência da marca); d) estruturação da interface com o cliente (ações que serão realizadas para gerar a experiência); e) comprometimento com a inovação contínua (ideia de que as inovações da empresa devem refletir a plataforma experiencial).

Prahalad e Ramaswamy (2004) ressaltam que o desafio das organizações é criar um ambiente de experiência que impacte no interior do indivíduo, podendo este criar sua própria e única experiência 
personalizada. Para tanto, apresentam o Modelo DART (Diálogo, Acesso, Risco e Transparência). Os mesmos autores procuram indicar os pontos a serem trabalhados pelas empresas que buscam a interação com seus consumidores na construção compartilhada de valor através de experiências, considerando quatro elementos sustentadores: diálogo, acesso, redução de riscos e transparência (Figura 1).

De forma sintética, o diálogo relaciona-se ao fato de que a comunicação unidirecional tradicional deve ser substituída por mecanismos que estimulam o fluxo bidirecional de informações, tornando o processo mais interativo a trazendo o consumidor para um papel ativo na criação da experiência. 0 acesso implica o desenvolvimento dos meios de contato entre empresa-consumidor, consumidor-consumidor que devem ser estruturados e coordenados pela empresa de forma a encorajar um processo contínuo de troca entre os diferentes atores. A redução do risco implica minimizar a assimetria de informações entre empresas e consumidores, reduzindo os riscos percebidos por ambas as partes. Por fim, a transparência remete à maior abertura por parte das empresas e, por consequência, maior transparência nas relações com seus consumidores.

Prahalad e Ramaswamy (2004) também reforçam o fato de que, pelo lado do mercado, consumidores atuam e interagem com diferentes comunidades temáticas, as quais representam elementos de identidade e autenticidade relacionados com valores pessoais e estilo de vida de cada indivíduo. De outra parte, a criação de experiências diferenciadas baseia-se fortemente na formação de redes entre diferentes empresas. Conforme Lusch e Vargo (2006), a criação de valor compartilhado baseia-se na contribuição de competências e habilidades trazidas por diferentes atores (consumidores, empresa, fornecedores, etc.) que proporcionam um resultado (serviço) distinto.

\section{Método}

0 método de pesquisa utilizado para este estudo é o estudo de caso que, de modo geral, representa a estratégica ideal a fim de responder a determinadas questões do tipo "como" e "porque" (YIN, 2005). No presente estudo, foi selecionada uma empresa cuja estratégia é assumidamente baseada no valor experiencial, constituindo uma oportunidade para contrapor propostas teóricas com o contexto real da empresa. Fundada em 1976, a rede varejista Gang tem como público-alvo os jovens consumidores e trabalha principalmente a linha de moda casual. Presente nos estados do Rio Grande do Sul e Santa Catarina, a Gang conta 33 lojas próprias e outros 150 pontos de venda multimarcas no Brasil.

Para a coleta de dados aplicaram-se os seguintes procedimentos de pesquisa: entrevistas em

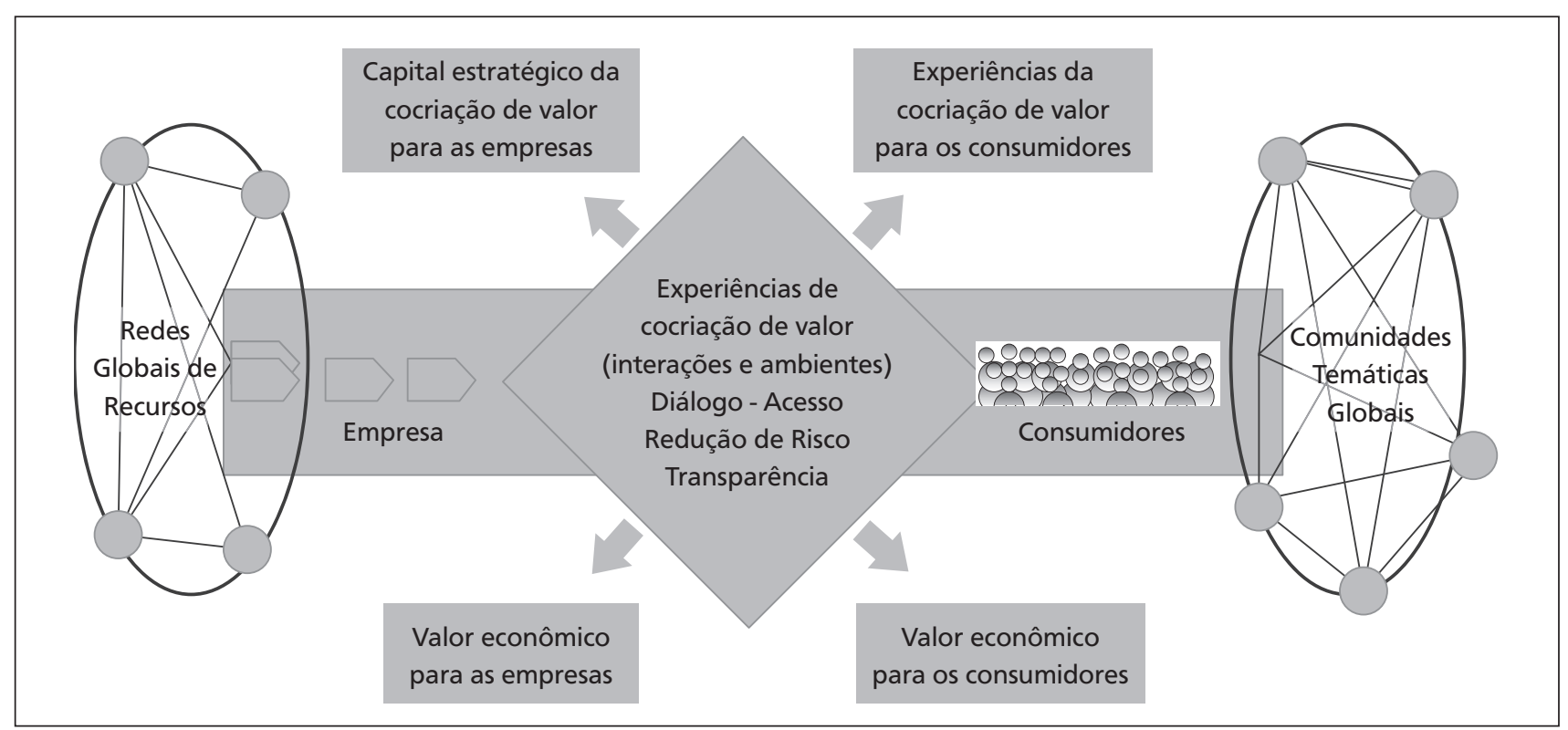

Figura 1 - Modelo DART

Fonte: adaptado de PRAHALAD; RAMASWAMY, 2004. 
profundidade, observação e análise de documentos. Foram realizadas duas entrevistas em profundidade, através de um roteiro semiestruturado, com os gestores da Gang, a saber: o diretor de Marketing e Vendas e o coordenador de Marketing e Vendas (caracterizados neste artigo como entrevistados 1 e 2). Essas entrevistas objetivaram compreender como o conceito de experiência foi apropriado pela empresa e de que forma a GEC foi concebida e transformada em ações específicas.

Posteriormente, foram realizadas observações em quatro lojas próprias da marca, localizadas em Porto Alegre, durante os dias 14 e 22 de dezembro de 2011, com duração aproximada de quatro horas por dia de observação. Esse procedimento buscou o maior entendimento de como a proposta experiencial é operacionalizada pela empresa, bem como de que forma empresa e consumidor fazem uso dos diferentes mecanismos de interação disponibilizados.

Por fim, foram analisadas fontes de dados secundários, incluindo os conteúdos do site e do blog da empresa, seu layout e troca de programação/informação no período de agosto de 2011 a janeiro de 2012, sendo analisados de forma quinzenal. Também se analisou o conteúdo proposto nas redes sociais Facebook, Orkut e Twitter no período de agosto de 2011 a fevereiro de 2012, quando os pesquisadores se afiliaram às redes sociais, passando a acompanhar os conteúdos postados pela marca durante esse tempo. Complementando esses procedimentos, foram analisadas as campanhas publicitárias realizadas pela marca no ano de 2011.

A análise dos dados foi realizada com base na análise de conteúdo, através da categorização temática, considerando as categorias de análise decorrentes dos modelos teóricos expostos anteriormente.

\section{Resultados}

A seguir, apresentam-se os principais resultados do estudo, considerando inicialmente as entrevistas com gestores; posteriormente, são destacados os aspectos observados nas lojas e os achados resultantes da análise de dados secundários.

\section{Entrevistas com os gestores}

Para Lasalle e Britton (2003), as experiências permitem ao consumidor vivenciar todos os momentos da relação com determinada empresa ou marca, a fim de que suas expectativas sejam alcançadas. Além disso, Pullman e Gross (2003) afirmam que a interação entre o consumidor e a marca ocorre através de diferentes elementos dessa empresa. Com base no exposto, nota-se que os gestores da Gang identificam elementos que extrapolam a ligação da marca Gang com os seus consumidores, indo além da relação consumidor/produto. Ou seja, na opinião dos gestores, a Gang oferece uma gama de pontos de contato que proporcionam diferentes formas de experiência para o seu público-alvo. Entre as formas de experiências descritas, o ponto de venda foi um importante ponto de contato analisado, pois ele foi pensado e construído a partir do que os gestores entendem como ideal e adequado para seus clientes:

A gente pensou como seria mais ou menos o quarto dele e tentou desenvolver isso. [A loja] tem internet para eles, tem a rádio Gang na qual eles escolhem as músicas dentro da loja, tem a TV Gang que é uma TV dentro da loja [...] é onde ele está se expressando, é ele que está falando (Entrevistado 2).

Por meio de um projeto desenvolvido por um especialista em visual merchandising, a Gang chegou ao conceito de extensão do quarto do jovem, ou seja, um ambiente de loja que imprimisse uma continuação do quarto desse adolescente:

Dentro dessa experiência de compra o PDV é sempre pensado como a continuação do quarto desse adolescente [...] a gente chama de bazar [...] tem um lounge com computador à disposição para eles acessarem a internet, tem a música que ele escolhe, então é o quarto 'dos sonhos' do adolescente (Entrevistado 1).

Dentro do conceito de experiência de loja, foram citados dois mecanismos trabalhados pela empresa que, além de fazerem parte do ambiente de loja, também se estendem à esfera virtual: TV Gang e Rádio Gang. A TV Gang, além de divulgar conteúdo e ter sua programação difundida nas lojas, também tem sua veiculação online, sendo uma forma de interação com o consumidor que vai além do ponto de venda: " $a T V$ Gang dentro da loja é mais para eles se verem, mas fora da loja ela tem uma interação enorme, eles adoram! A gente sempre tem e-mails e e-mails que eles pedem a TV Gang, então está sempre cheio!" (Entrevistado 2). Segundo o entrevistado 2, a TV Gang é um trabalho 
intenso de comunicação, que circula entre festas, saídas de colégios e eventos que interessam ao público-alvo, como forma de fazer os potenciais clientes se verem e se comunicarem.

A TV Gang é uma experiência bem legal que não envolve roupa, ela está dentro da loja, nas redes sociais, na internet, está disponível para todo mundo [...] é a TV Gang indo aos colégios, indo nas festas, nos lugares que o nosso público está para saber a opinião deles (Entrevistado 2).

Outras formas de experiências apontadas pelos gestores são as plataformas virtuais: o Twitter, o Facebook e o Orkut. 0 blog da marca, alimentado por uma correspondente radicada em Londres, também é um importante meio de proporcionar a experiência citado pelos gestores. 0 blog é alimentado com informações que interessem ao público-alvo, como clipes musicais, tendências de moda, informações sobre eventos e shows: "eles estão sempre conectados, querem as novidades [...] tem a ligação com celebridades, eles querem notícias do meio [...] então a gente procura trabalhar também no nosso blog alimentando conteúdo" (Entrevistado 1).

Segundo os gestores da Gang, oferecer vários pontos de contato e proporcionar diferentes formas de experiência para os consumidores da marca exige um trabalho de gerenciamento perspicaz e cauteloso. Dando respaldo a esse pensamento, Gentile, Spiller e Noci (2007) afirmam que a experiência deve gerar valor não só para a empresa, mas também para os clientes, em que o gerenciamento dos componentes que fazem parte de uma experiência de consumo acabam se tornando um dos grandes desafios enfrentados pelas empresas (SCHMITT, 2004). 0 entrevistado 1 afirma que as 33 lojas da marca possuem Facebook próprio, no qual eles têm liberdade para alimentar conteúdo com interesses dessa comunidade, porém sempre sendo monitorados pela gerência de marketing: "a gente estimula que eles compartilhem tudo o que a Gang-mãe publica e, é claro, que faça o seu trabalho pessoal de tirar uma foto e dizer: aqui em tal cidade ou aqui em SC [...] nós seguimos com esse monitoramento" (Entrevistado 1).

Os gestores da Gang entendem que o posicionamento da marca está associado principalmente à interação da marca com seus consumidores, através de diversos pontos de contato, já citados anteriormente. Gentile, Spiller e Noci (2007) reiteram que as experiências de consumo são formas de interação entre os clientes com uma organização ou marca que provoque uma reação. A seguir, destaca-se o ponto de vista do entrevistado 1, que reforça essa ideia:

O nosso objetivo, em termos de marketing, é estar presente o máximo possível na vida desse cliente. Fazê-lo entrar em contato com a marca diversas vezes ao dia. Assim, o trabalho das redes sociais é inevitável [...] as respostas são instantâneas quando os clientes perguntam [...] então essa relação faz com que esse contato fique permanente.

Outro indício deste posicionamento, baseado na interação com os consumidores e principalmente na iniciativa da marca Gang de estar próxima do seu cliente, pode ser constatado na citação a seguir: " $a$ gente quer falar com ele, a gente quer interagir com ele, a gente quer que ele saiba o que está acontecendo com a gente [...] e nós queremos saber o que está acontecendo com ele" (Entrevistado 2).

É interessante observar que os gestores reconhecem a existências de alguns percalços na operacionalização da estratégia. Mesmo ressaltando que existiram alguns casos em que esta interação não foi tão positiva, como algumas críticas nas plataformas virtuais, algumas considerações negativas e até mesmo revoltas, os gestores entendem que não chega a ser um real problema para a marca, conforme verbaliza o entrevistado 2 :

Eu levo para um lado positivo, porque assim como eu posso dizer que na Gang só tem roupa preta, mas tem gente que ama roupa preta ou que na Gang só tem roupa muito colorido, mas tem gente que gosta de roupa muito colorida [...] então mesmo negativo para um lado, pode ser positivo para o outro (Entrevistado 2).

\section{Observações nas lojas}

A partir das observações realizadas em algumas lojas da marca, de modo geral o que se observou foi que todas elas seguem o mesmo padrão de atendimento e layout, seguindo o conceito proposto pela Gang. Partindo-se do pressuposto de proporcionar uma situação de consumo a ser vivenciada pelo consumidor (SCHMITT, 2002), o que se constatou ao longo das observações foi a preocupação da Gang em oferecer um ambiente condizente 
e adequado ao seu público-alvo. Notou-se que todas as lojas oferecem o mesmo padrão de layout, tendo pequenas diferenças ou adaptações realizadas em relação ao espaço, pois elas possuem tamanho e estruturas diferenciados. Ao analisar-se a fachada das lojas, viu-se que elas obedecem o mesmo padrão: fachada de vidro, sem portas, o que torna a loja um ambiente convidativo aos consumidores, estendendo o ambiente para fora da própria loja, tornando-o mais próximo do consumidor (Figura 2).
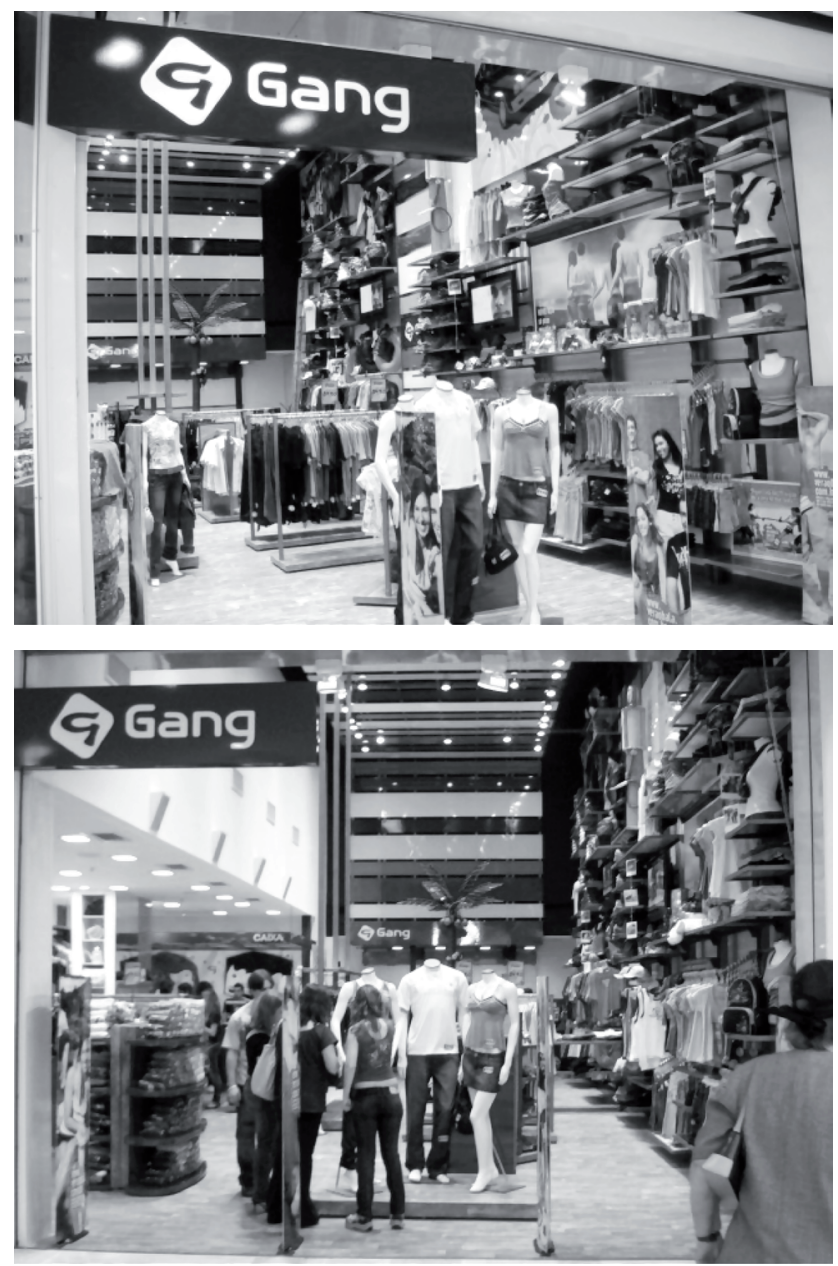

Figura 2 - Loja Gang

Fonte: Dados da pesquisa.

Todas as lojas são bastante coloridas, utilizam a mesma cartela de cores, com pé direito alto, formado por uma espécie de faixas de cores correspondentes às cores utilizadas nas campanhas e materiais promocionais da marca. As lojas são bem iluminadas, existem móveis fixos e também mobiliários móveis, que permitem maior mobilidade nas lojas, favorecendo a mudança rápida no layout, de acordo com a necessidade de cada uma delas. Também se constatou que as lojas possuem um móvel semelhante a um armário geralmente utilizado em quartos, no qual são expostos os produtos de bazar (acessórios, luminárias, agendas, porta-caneta, relógios, ursos de pelúcia, entre outros).

Um fator que favorece a ideia de as lojas estarem em constante renovação são os materiais promocionais de que dispõem referentes à comunicação que a empresa está trabalhando, modificados com frequência, conforme a troca de campanha ou de acordo com promoção específica. Os provadores são representados por números, que variam de um a seis, de acordo com o número de provadores existente em cada loja, e nele existe a opção do consumidor apertar um botão caso precise do auxílio de um vendedor.

Outro ponto de destaque é a adequação dos atendentes aos consumidores da marca, sendo todos jovens, vestidos de modo muito semelhante aos consumidores da marca. Observou-se que a preocupação de usar linguagem condizente ao público-alvo pode ser percebida em toda a loja, desde a forma como os vendedores se comunicam com seus clientes, incluindo gírias e expressões peculiares, como em relação aos materiais promocionais e placas informativas dentro das lojas. Nos provadores, há mensagens convidativas para utilizar a internet dentro da loja: "Confira com as gatinhas se ficou bacana"; "Tá na dúvida? Consulte os universitários"; "Uhmm. Sabe não? Mostra pras gurias"; seguido da frase "MSN com webcam ali fora". Ou ainda, em relação aos avisos e informativos obrigatórios, todos foram adequados à linguagem dos jovens: "Tá de aniversário? Faça sua lista e deixe com a gente"; "Mete o dedo e escolhe o som da rádio que te entende"; "Área reservada para a galera da Gang = acesso restrito" e "Não queime o filme, porque você está sendo filmado".

Brakus, Schmitt e Zarantonello (2009) afirmam que as experiências podem ocorrer em diferentes momentos e de diferentes formas. Fazendo a análise acerca das diversas fontes capazes de proporcionar experiências, notou-se que a Gang trabalha vasta linha de estímulos capazes de envolver os clientes (conforme Figura 3), fazendo-os vivenciar uma experiência: a TV Gang, que proporciona conteúdo aos jovens ininterruptamente (clipes de músicas, reportagens e entrevistas com legendas), permitindo ao jovem acompanhar o conteúdo da TV no ambiente de loja; a rádio Gang, na qual os consumidores podem 
escolher a música que gostariam de ouvir enquanto realizam suas compras, através de músicas características ao público jovem. Também disponibiliza um espaço, chamado lounge, próximo a um computador com internet, com o aviso: "Internet liberada, aqui você não tem irmãos para dividir o computador", que pode ser acessado pelos consumidores. 0 lounge está localizado próximo aos provadores, com pufes, sofás e revistas de interesse dos jovens, o que favorece um ambiente de confraternização entre consumidores, e entre consumidores e funcionários. Por fim, há o mural de recados, uma lousa branca sobre a qual os consumidores podem escrever o que tiverem vontade.

\section{Análise de dados secundários}

A partir da análise do que a Gang descreve em seu site como sendo seus objetivos principais, observou-se que um importante princípio da marca é a renovação constante, visando a conseguir atender às diferentes gerações de jovens que por ali passaram ao longo de sua história. Outra característica do site que vai ao encontro da proposta de experiência baseada em uma perspectiva experiencial, caracterizada por um fluxo de fantasias, sentimentos e diversão, é a linguagem, o tipo e a forma de informação nele exposto (HIRSCHMAN; HOLBROOK, 1982). No primeiro momento, entende-se que o site é uma extensão do universo Gang, já observada nas lojas próprias da marca, ou seja, o site pode ser considerado um portal da marca que dá acesso às informações básicas referentes à marca, às redes sociais, à loja virtual e a uma variedade de estímulos caracterizadas como formas de experiência propostas pela marca e que serão analisadas detalhadamente a seguir.
Ao longo da observação, percebe-se que a Gang renova o site com certa frequência, atitude que mostra ao consumidor a constante renovação da marca. A parte inicial do site é bastante colorida, com imagens voltadas ao público jovem, e utiliza uma linguagem informal, comum em todo o site. A primeira imagem do site analisada mostra links, a partir dos quais o público acessa informações básicas da Gang: seu histórico; a localização das lojas da marca; as campanhas publicitárias realizadas ao longo dos anos; informações relacionadas aos revendedores da marca, um link com informações para quem desejar trabalhar na empresa e o contato. 0 site também apresenta links de acesso às redes sociais da marca - o Facebook, o Orkut, o Twitter e o blog -, além de um link que permite acessar a loja on-line da marca.

A segunda imagem do site analisada relaciona-se à TV Gang, que é um canal da Gang, com conteúdo próprio, que tem sua veiculação no próprio site, nas lojas da marca e em um canal da Gang na rede YouTube, que pode ser acessado por um link também via site. A TV Gang é um canal proposto pela marca para dar voz aos jovens, no qual são propostas pautas de discussão e assuntos de interesse, nos quais eles podem posicionar-se, opinar e, posteriormente, verem a si próprios e seus amigos, colegas ou artistas conhecidos do público na TV Gang. A TV contém, basicamente, três canais de conteúdo. 0 primeiro deles é o "Fala Sério", um canal com assuntos considerados importantes para esse público e de cunho social, em que a equipe Gang, após visita aos colégios ou eventos específicos para captar imagens e opiniões dos jovens, posta os dados captados em relação às pautas propostas. O segundo canal é o "Chutando o Balde", que é uma forma de o público fazer críticas, demonstrar a sua revolta e descontentamento em relação a
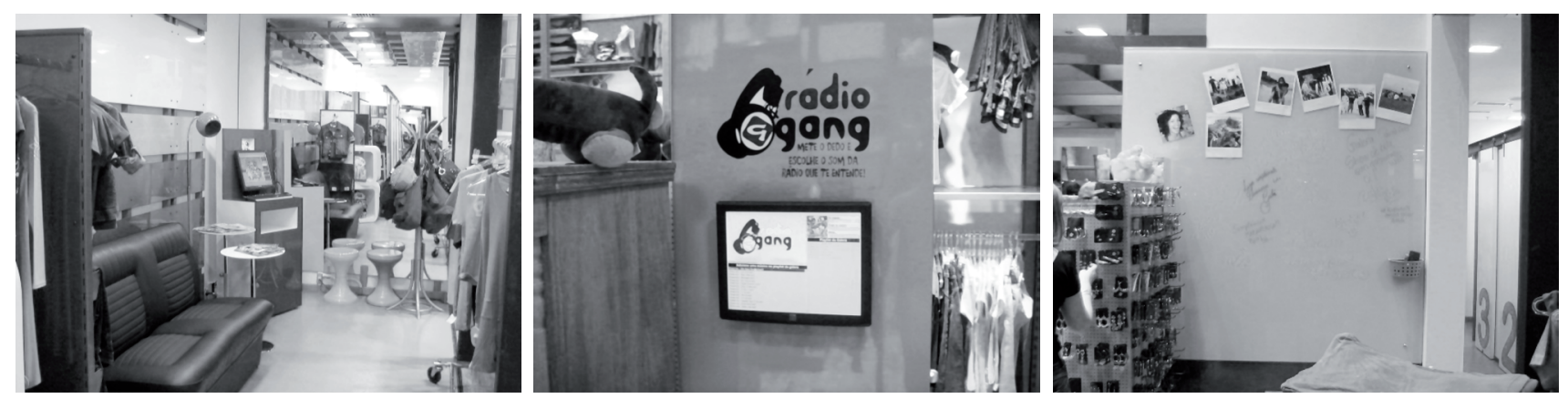

Figura 3 - Detalhes do lounge, Rádio Gang e mural

Fonte: Dados da pesquisa. 
determinado assunto. Nesse canal, não existe uma pauta predeterminada, a equipe encontra jovens em eventos e shows que estão acontecendo na cidade e lhes permite a liberdade de fazer a sua crítica a assuntos do momento, ou assuntos que lhes interessam particularmente. 0 terceiro canal, denominado "Zueira", pode ser considerado o mais livre da marca, com vídeos de campanhas publicitárias da Gang, vídeos que estão circulando na internet, considerados de interesse ao jovem consumidor Gang, entrevistas e clipes de músicas.

Outra parte do site analisada engloba a Rádio Gang que, da mesma forma que a TV, tem sua veiculação tanto nas lojas quanto no site, e é uma espécie de rádio particular da marca, em que são propostas seleções de músicas, divididas em subcategorias, com uma linguagem própria, informal e divertida: Top 10, Pré-Balada, Descornado, Tenso, TahRolando, Love Songs, Trip; e também há um convite de acesso à marca para que os consumidores façam parte do universo Gang. A proposta de unificação entre lojas, site e redes sociais fica evidente nesse convite, através da ideia de fazer parte de uma conta unificada da Gang, denominada Gang Fãs - fãs, amigos e seguidores convidando o jovem a fazer um cadastro para receber novidades e informações sobre a marca.

Por fim, a última parte do site analisada, que engloba serviços oferecidos pela Gang que vão além dos próprios produtos da marca, oferecendo games criados especificamente para a Gang, que podem ser jogados pelos consumidores da marca; dicas de cuidados com as peças de roupas da marca; a opção do cartão-presente, em que os consumidores podem creditar um valor no cartão e dar de presente, podendo o serviço ser feito através do site, não sendo necessária a ida do consumidor até a loja para a compra do cartão. Também há uma seção de patrocínio, em que o consumidor faz um cadastro e a Gang se dispõe, mediante avaliação, a patrocinar um evento desse consumidor e de seus amigos.

O blog é outra forma de proporcionar experiência para os consumidores da marca, analisado durante a coleta de informações, que vai ao encontro das ideias de Mathwick, Malhotra e Rigdon (2001) de que o valor percebido a partir de uma experiência pode ser oriundo tanto nas interações com o uso direto dos produtos, quanto na apreciação a distância desses bens. Denominada "Blogang", a página é alimentada diariamente por uma correspondente principal que vive em Londres. Além dela, o blog conta com a participação de outros correspondentes que estão no Brasil ou ainda com convidados que alimentam a página quando há uma pauta específica; nesse caso, o blog informa quem é o convidado e o assunto a ser tratado.

Com base no pensamento de Gentile, Spiller e Noci (2007), de que as experiências são um somatório de interações entre marca e clientes que geram uma resposta, as redes sociais utilizadas pela marca Facebook, Orkut e Twitter - podem ser consideradas outra importante fonte de informação (documento) analisada. Durante a análise, percebeu-se que as redes sociais são uma extensão de conteúdo e informações que circulam nas lojas, no site e no blog da marca, pois a Gang faz com que toda a informação da marca circule de forma contínua e adequada em todas as suas propagadoras de conteúdo. Analisandose especificamente o Facebook, percebe-se que, das redes sociais utilizadas, é com essa rede que o consumidor mais interage, sendo alimentada diariamente com conteúdo da Gang e com comentários dos consumidores da marca. 0 Facebook da marca estrutura-se da seguinte forma: há uma página da Gang-mãe - com 4.408 curtições - ou seja, uma página no Facebook que pode ser considerada a principal da marca, em que as informações globais da marca são expostas. Além disto, cada loja própria da Gang tem a sua própria página do Facebook, com autonomia para inserir conteúdo específico e do interesse de cada uma das lojas, sempre alinhadas à página da Gang-mãe, formando uma rede unificada de informação.

0 Twitter, com aproximadamente 8.400 seguidores, representa uma rede social capaz de prover informações mais rápidas em relação à marca, mas com limitação de espaço/quantidade de informações. Considerando-se o tipo de informação que a Gang veicula no Twitter, observa-se que são informações, curiosidades e enquetes, que incentivam a rápida resposta dos consumidores da marca. Por fim, a comunidade da marca no Orkut, apesar do maior número de membros (12.000), é a que tem menor interação com os consumidores. Nos primeiros meses de observação, notou-se que a Gang tentava interagir com seus consumidores através dos fóruns, local em que se cria determinado tópico que incentive o consumidor a interagir com a marca, mas mesmo com esse esforço não houve interação. Nos últimos meses de observação, com a mudança no formato da própria rede social, que passou a oferecer maiores opções de comandos, essa interação passou a ser um 
pouco maior, mas continuou insignificante em relação à interação nas demais redes sociais.

Finalmente, ao se analisarem as campanhas publicitárias da marca no ano de 2011, constatou-se que a empresa busca uma comunicação capaz de dizer tudo o que o consumidor gostaria de falar, mas não encontra espaço suficiente. Com o slogan "A loja que te entende", a marca reafirma o compromisso de dar voz ao seu consumidor. Com um vídeo comemorativo aos seus 35 anos, intitulado "Paz e Amor" - com a trilha sonora utilizando a música "Paz e Amor" da banda Nenhum de Nós - a Gang apresenta a evolução do seu público-alvo. A Gang também mostra a evolução da sua logomarca, com as mudanças de layout que ocorreram nos últimos anos, e assina o filme com a frase: "Gang, a loja que te entende, há 35 verões". Esse vídeo reforça o posicionamento da marca de estar em constante transformação, acompanhando a evolução e o crescimento do seu público-alvo. Igualmente, verifica-se que em todas as campanhas a Gang trabalha o conceito de dar voz ao jovem, utilizando linguagem informal, que aproxima a marca do adolescente. Por exemplo, na campanha intitulada "Volta das Férias", os consumidores eram convidados a enviar uma foto da sua turma, respondendo à pergunta: "Por que você e sua galera merecem ir para Porto Seguro na maior regalia?", ou seja, as expressões "regalia" e "galera", gírias utilizadas pelos jovens, inseridas em toda a campanha, aproximam a marca da linguagem informal.

Outra campanha analisada comprova essa aproximação da Gang com os interesses do seu público-alvo, intitulada "Rock". Nela são utilizadas imagens coloridas e com layout característico do público adolescente, com trechos de algumas famosas músicas de rock. A campanha referente ao dia dos namorados, mesmo não utilizando texto, estava baseada em imagens de jovens usando produtos jeans da Gang, com um forte apelo à sensualidade. Além disso, a Gang reafirmou a utilização de campanhas com um teor de ousadia, ao utilizar imagens de jovens com partes do corpo à mostra. A última campanha analisada, denominada "Fãs, Amigos e Seguidores", é uma campanha que unifica todo o posicionamento da Gang baseado em diversos pontos de contato entre consumidores e marca, através do site, do blog, do canal TV Gang no YouTube e das redes sociais Facebook, Orkut e Twitter. A campanha convida os consumidores Gang a fazerem parte do universo da marca, associando-se a um dos meios já mencionados, para receberem informações do que está acontecendo com a marca.

\section{Conclusões}

Ao se analisarem os resultados deste estudo de caso, observou-se que a proposta da Gang baseia-se em uma perspectiva experiencial que compreende a capacidade multissensorial dos consumidores, o que incentiva a empresa a desenvolver ofertas capazes de transmitir sentimentos e emoções (SCHMITT, 2002).

Por outro lado, segundo Gentile, Spiller e Noci (2007), as marcas devem considerar os aspectos funcionais e de performance do negócio na proposta de suas experiências. 0 apelo da marca às características mais objetivas da compra pode ser constatado tanto nas verbalizações dos entrevistados, ao relatarem que a Gang se preocupa em oferecer um produto com qualidade e um preço considerado justo, quanto nas observações nas lojas, pois se identificou a existência de grande quantidade de materiais promocionais e de divulgação dos produtos e das promoções da marca, além de um estímulo ao consumidor pela procura e experimentação dos produtos nas lojas, através de sua disposição. Em relação aos documentos analisados, verificou-se que a Gang utiliza o seu site, blog, redes sociais e campanhas como forma de divulgar produtos, lançamentos e promoções da marca.

Mesmo considerando as concepções presentes na perspectiva utilitarista do consumo citada por Addis e Holbrook (2001), entende-se que o foco hedônico relacionado aos aspectos fantasiosos, multissensoriais e emocionais da experiência de consumo (HIRSCHMAN; HOLBROOK, 1982) são as bases fundamentais para a proposta oferecida pela Gang. Essa proposta de experiência da marca pode ser compreendida no relato dos gestores, em que se constata a preocupação em proporcionar aos seus consumidores produtos e serviços baseados em comportamento, estilo e informação. Outro meio capaz de caracterizar a perspectiva hedônica presente na proposta da marca foi analisado durante as observações. A marca oferece estímulos capazes de gerar sentimentos nos consumidores no momento da compra, seja através da ideia de extensão do quarto do jovem no ponto de venda, seja pelo comportamento dos seus funcionários, que atuam como consultores de moda e estilo. 
Essas percepções convergem para o que foi analisado do ponto de vista da GEC proposta por Schmitt (2002), ao delimitar que os profissionais de marketing devem compreender os cenários e ambientes mais adequados para que as experiências possam ocorrer efetivamente, fornecendo os meios "provedores de experiência". A empresa busca de forma constante a interação com seus consumidores, seja através do ambiente de loja, com estímulos que visam à interação com a marca, e a interação desses consumidores com os funcionários da loja, seja por meio dos diversos pontos de contato entre marca e consumidor: o site, o blog e as redes sociais.

Gentile, Spiller e Noci (2007) e Schmitt (2004) sugerem desenvolver experiências baseadas na inovação, sendo este foco identificado na marca. As entrevistas com os gestores reafirmam a preocupação em estar em constante transformação, oferecendo mecanismos de experiência até então não identificados no contexto varejista gaúcho, com foco no público jovem. Neste sentido, destacam-se a Rádio Gang, a TV Gang, o lounge com internet nas lojas e o intenso foco de comunicação, difundido nas redes sociais, ferramenta ainda incipiente e embrionária em relação aos meios tradicionais de comunicação. 0 foco em inovação também pode ser observado nas lojas no que tange à disposição e à troca dos mobiliários e às mudanças de programação visual (materiais promocionais, banners, materiais de comunicação), pois com essas pequenas alterações há a impressão de que as lojas estão diariamente se renovando.

0 que difere a proposta de gestão baseada em perspectiva experiencial de uma proposta tradicional, relacionada principalmente à gestão dos 4Ps de marketing, é a percepção do consumidor como um agente ativo na criação da experiência e, consequentemente, na geração de valor (diferentemente da visão tradicional, na qual o consumidor é passivo, tão somente recebendo um "pacote" de valor proporcionado pelo mix de marketing). $\mathrm{Na}$ GEC o ponto de partida é uma análise aprofundada do contexto do consumidor, através de suas necessidades, preferências e estilos de vida (SCHMITT, 2004). Nesse caso, nota-se a preocupação da Gang em oferecer uma proposta de gestão de experiência em estreita colaboração com o mundo do seu consumidor. Uma segunda etapa referida pelo autor está em oferecer uma representação multissensorial e multidimensional de uma experiência, caracterizada no caso da Gang pelos múltiplos pontos de contato entre empresa e consumidor oferecidos pela marca, já analisados anteriormente.

De forma complementar, é possível verificar que os elementos sustentadores da experiência propostos no Modelo DART (PRAHALAD; RAMASWAMY, 2004) estão igualmente presentes. A partir dos diferentes canais de interação a Gang busca estimular e "conversar" continuamente com seus consumidores. O PDV, então considerado simplesmente o "ponto de venda" de produtos e transferência de valor, passou a ser planejado como um "ponto de experiência" estimulando a interação do consumidor com a empresa e com outros consumidores. Outros canais de contato, como redes sociais, igualmente ampliam o diálogo com o consumidor, fazendo da comunicação um processo compartilhado (e não apenas um fluxo unidirecional de informações da empresa para o mercado). Em relação ao acesso, mais do que experiências com produtos, a Gang busca proporcionar experiências com a marca, proporcionando que o consumidor aproxime-se da empresa independentemente da compra/uso de um produto. Nesse sentido, alinhada com seus objetivos estratégicos, a Gang estimula o consumo da marca e não apenas de produtos. A forte presença da marca nas redes sociais e nos meios de comunicação complementares às lojas e mídias tradicionais amplia esta condição. Risco e transparência são os componentes menos intensamente identificados no presente caso. Porém é possível concluir que a forte interação com o consumidor, tornando a Gang uma marca presente na vida de seus consumidores, implica a redução dos riscos inerentes ao negócio, em particular possibilitando uma comunicação mais alinhada em termos de linguagem e de interesses do público-alvo. Além disto, reforça a capacidade da empresa ajustar as demais dimensões de sua oferta ao estilo de vida do consumidor. A Figura 4 apresenta uma ilustração de como cada componente do modelo DART pode ser identificado na proposta da Gang.

A análise do caso aqui descrita contribui para um melhor entendimento da implantação estratégica da GEC. Em linha com os questionamentos levantados por Brasil (2007), é possível observar que o caráter contínuo de uma experiência é não apenas possível, como necessário às empresas de varejo. Contrapondo parcela de autores que defendem o caráter excepcional e extraordinário das experiências de consumo (PINE II; GILMORE, 1998; DUBÉ; LÊ BEL; SEARS, 2003; FARIAS, 2010), o 


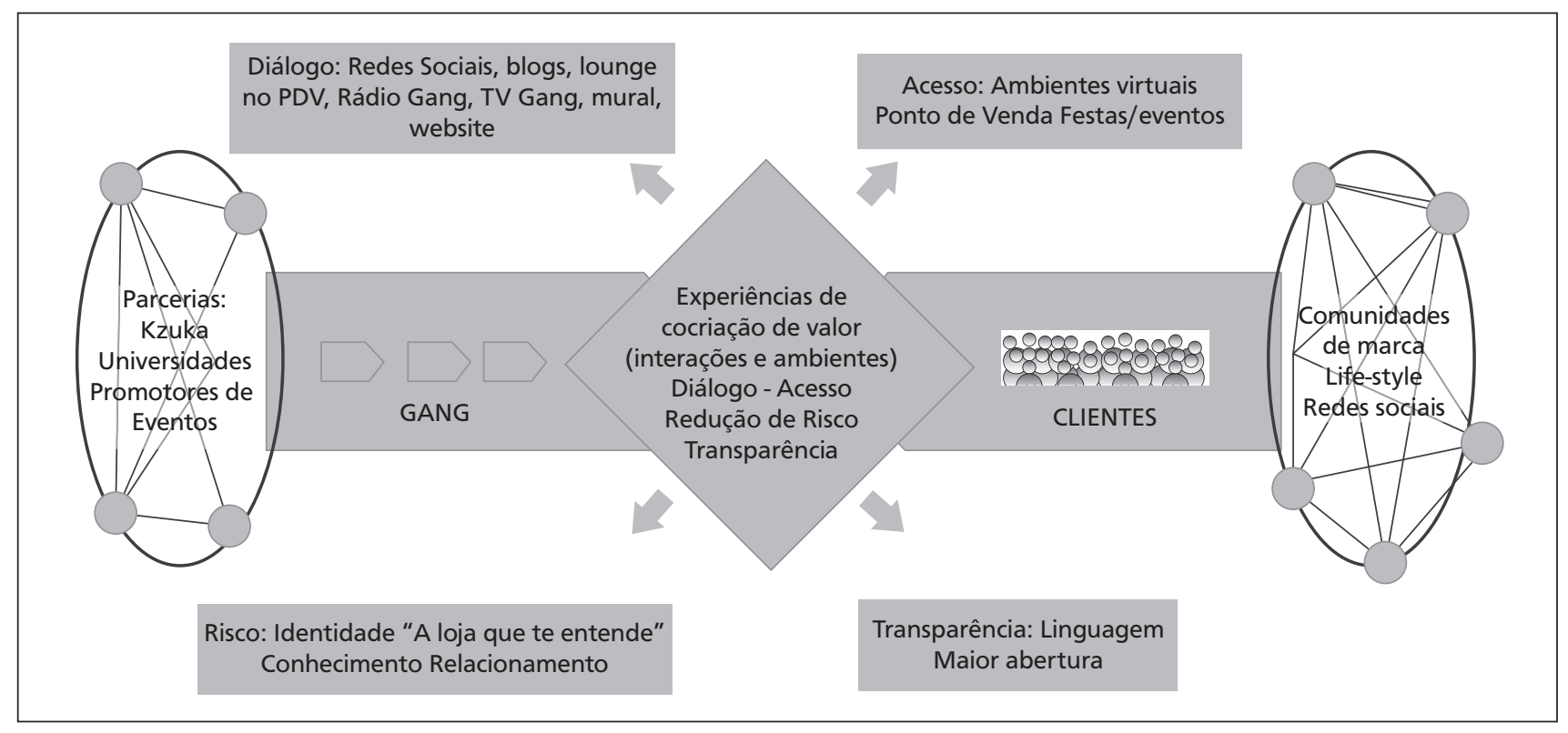

Figura 4 - Modelo DART aplicado à Gang

Fonte: Dados da pesquisa.

estudo demonstrou a perspectiva experiencial sob a ótica de contínua relação e interação com os consumidores, conforme Schimtt (2004) e Verhoef et al. (2009) destacam. Além disso, demonstra que o caráter individual e autêntico da experiência pode ser obtido por meio da implantação de mecanismos de interação e diálogo nos quais cada consumidor obtém aquilo que considera valor, seja no compartilhamento do processo de compra via web, na manifestação de opiniões na TV Gang, seja simplesmente na troca de informações no blog.

Considerando-se os desafios da pesquisa, relacionados ao tema das experiências de consumo, o presente artigo enfocou apenas a perspectiva da empresa em relação à GEC. Caberia, também, pesquisar a perspectiva dos consumidores em relação à percepção sobre a experiência proposta, além de comportamentos resultantes e atitudes em relação à marca. Como reforço no processo de planejamento da GEC, relevantes contribuições podem advir de estudos focados na relação entre a experiência de consumo e o estilo de vida, considerada por alguns autores como a base para a proposta de experiências positivas (SCHMITT, 2002; 2004; GENTILE; SPILLER; NOCI, 2007). Por fim, investigar as consequências do foco experiencial representa uma ampla oportunidade de pesquisa, sobretudo em relação a estudos que explorem quais medidas permitiriam às empresas mensurar o resultado do investimento na adoção da GEC.

\section{Referências}

ADDIS, M.; HOLBROOK, M. On the conceptual link between mass customization and experiential consumption: an explosion of subjectivity. Journal of Consumer Behavior, v. 1, n. 1, p. 50-66, 2001.

BRASIL, V. Experiência de consumo: aspectos conceituais, abordagens metodológicas e agenda de pesquisa. In: ENCONTRO DA ASSOCIAÇÃO NACIONAL DOS PROGRAMAS DE PÓS-GRADUAÇÃO EM ADMINISTRAÇÃO, 31., 2007, Rio de Janeiro. Anais... Rio de Janeiro: EnANPAD, 2007.

BAUER, M.; GASKELL, G. Qualitative researching with text, image, and sound. London: Sage, 2008.

BRAKUS, J.; SCHMITT, B.; ZARANTONELLO, L. Brand experience: what is it? How is it measured? Does it affect loyalty? Journal of Marketing, v. 73, n. 3, p. 52-68, may. 2009.

CARÙ, A.; COVA, B. Revisiting consumption experience: a more humble but complete view of the concept. Marketing Theory, v. 3, n. 2, p. 267-286, 2003.

CARÙ, A.; COVA, B. Consuming experience. London: Routledge, 2007. 
DUARTE, J.; BARROS, A. Método e técnica de pesquisa em comunicação. São Paulo: Atlas, 2006.

DUBÉ, L.; LE BEL, J.; SEARS, D. From customer value to engineering pleasurable experiences. Cornell Hotel and Restaurant Administration Quarterly, v. 44, n. 5-6, p. 124130, 2003.

FARIAS, A. Store atmospherics and experiential marketing: a conceptual framework and research propositions for an extraordinary customer experience. In: ENCONTRO DE MARKETING, 4., 2010, Florianópolis. Anais... Florianópolis: ANPAD, 2010.

GENTILE C.; SPILLER N.; NOCI, G. How to sustain the customer experience: an overview of experience components that co-create value with the customer. European Management Journal, v. 25, n. 5, p. 395-410, oct. 2007.

GIL, A. Como elaborar projetos e pesquisas. 5. ed. São Paulo: Atlas, 2010.

GREWAL, D.; LEVY, M.; KUMAR, V. Customer experience management in retail: an organizing framework. Journal of Retailing, v. 85, n. 1, 2009.

HIRSCHMAN, E. C.; HOLBROOK, M. B. Hedonic consumption, emerging concept, methods and propositions. Journal of Marketing, v. 46, n. 3, p. 90-102, 1982.

LASALLE, D.; BRITTON, T. Priceless: turning ordinary products into extraordinary experiences. Boston: Harvard Business School Press, 2003.

LUSCH, R.; VARGO, S. Service-dominant logic. Marketing Theory, v. 6, n. 3, p. 281-288, 2006.

LUSCH, R.; VARGO, S.; O'BRIEN, M. Competing through service: insights from service-dominant logic. Journal of Retailing, v. 83, n. 1, p. 5-18, 2007.

MATHWICK, C.; MALHOTRA, N.; RIGDON, E. Experiential value: conceptualization, measurement and application in the catalog and internet shopping environment. Journal of Retailing, v. 77, n. 1, p. 39-56, 2001.
MEYER, C.; SCHWAGNER, A. Understanding customer experience. Harvard Business Review, feb. 2007.

PRAHALAD, C. K.; RAMASWAMY, V. The new frontier of experience innovation. Sloan Management Review, v. 44, n. 4 , p. $12-18,2003$.

PRAHALAD, C. K.; RAMASWAMY, V. Co-creation experiences: the next practice in value creation. Journal of Interactive Marketing, v. 18, n. 3, p. 5-14, 2004.

PINE II, B. J.; GILMORE, J. H. The experience economy. Boston: Harvard Business School Press, 1998.

PULLMAN, M.; GROSS, M. Welcome to your experience: where you can check out anytime you'd like, but you can never leave. Journal of Business and Management, v. 9, n. 3, p. 215-232, 2003.

SCHMITT, B. H. Marketing experimental. São Paulo: Nobel, 2002.

SCHMITT, B. H. Gestão da experiência do cliente. Porto Alegre: Bookman, 2004.

VERHOEF, P. et al. Customer Experience Creation: determinants, dynamics and management strategies. Journal of Retailing, v. 85, n. 1, p. 31- 41, 2009.

YIN, R. Estudo de caso: planejamento e métodos. São Paulo: Bookman, 2005.

YUAN, Y.; WU, C. Relationship among experiential marketing, experiential value and customer satisfaction. Journal of Hospitality and Tourism Research Thousand Oaks, v. 32, n. 3, p. 387-410, 2008.

Recebido: 01/08/2012 Received: 08/10/2012

Aprovado: 01/09/2012

Approved: 09/01/2012 